\title{
Shared care follow-up of patients with B- cell neoplasms based on nurse-led telephone consultations and PRO-data: a feasibility study from the North Denmark Region
}

Mia Sommer ${ }^{1,2,3,4^{*}}$ (D, Lone Frandsen ${ }^{1}$, Paw Jensen ${ }^{1,4}$, Søren Ramme Nielsen ${ }^{1}$, Lars Børty Nielsen ${ }^{1}$, Rasmus Froberg Brøndum 1,2,4 Martin Bøgsted ${ }^{1,2,4}$, Jakob Madsen ${ }^{1}$, Marianne Tang Severinsen 1,4, Erik Elgaard Sørensen ${ }^{2,3}$, Mette Grønkjær ${ }^{2,3}$ and Tarec Christoffer El-Galaly ${ }^{1,2,4}$

\begin{abstract}
Background: Patients with B-cell neoplasms in remission are monitored with regular physician visits at the hospital. The current standard follow-up procedure is not evidence-based or individualized to patient needs. To improve and individualize the follow-up, we investigated the feasibility of a shared care follow-up initiative, with alternating physician visits and nurse-led telephone consultations and assessments based on patient-reported outcome (PRO) data.

Methods: Patients $\geq 18$ years diagnosed with B-cell neoplasms were eligible for the study when they were in remission and stable without treatment for at least 6 months. Patients were assigned to alternating visits with physicians and nurse-led telephone consultations. The nurse-led telephone consultations were based on PROs, which were collected with the European Organization for Research and Treatment of Cancer questionnaire (EORTCQLQ-(30), the Myeloproliferative Neoplasm - Symptom Assessment Form, and the Hospital Anxiety and Depression Scale. Patients completed questionnaires before every nurse-led consultation. We also applied the Patient Feedback Form to survey patient acceptance of the requirement of questionnaire completion. We applied descriptive statistics, in terms of counts (n) and proportions (\%), to describe the study population and all endpoints.

\footnotetext{
* Correspondence: m.sommer@rn.dk

'Department of Hematology, Aalborg University Hospital, Sdr. Skovvej 15, DK-9000 Aalborg, Denmark

${ }^{2}$ Department of Clinical Medicine, Aalborg University, Aalborg, Denmark

Full list of author information is available at the end of the article
}

(c) The Author(s). 2020 Open Access This article is licensed under a Creative Commons Attribution 4.0 International License, which permits use, sharing, adaptation, distribution and reproduction in any medium or format, as long as you give appropriate credit to the original author(s) and the source, provide a link to the Creative Commons licence, and indicate if changes were made. The images or other third party material in this article are included in the article's Creative Commons licence, unless indicated otherwise in a credit line to the material. If material is not included in the article's Creative Commons licence and your intended use is not permitted by statutory regulation or exceeds the permitted use, you will need to obtain permission directly from the copyright holder. To view a copy of this licence, visit http://creativecommons.org/licenses/by/4.0/ The Creative Commons Public Domain Dedication waiver (http://creativecommons.org/publicdomain/zero/1.0/) applies to the data made available in this article, unless otherwise stated in a credit line to the data. 
(Continued from previous page)

Results: Between February 2017 and December 2018, 80 patients were enrolled. Adherence, measured as the recruitment rate, was 96\% (80/83), and the drop-out rate was 6\% (5/80). During the study period, 3/80 (4\%) patients relapsed, and 5/80 (6\%) patients returned to the standard follow-up, because they required closer medical observation. Relapses were diagnosed based on unscheduled visits requested by patients $(n=2)$ and patient-reported symptoms reviewed by the nurse $(n=1)$. The response rate to questionnaires was $98 \%$ (335/341). A total of 58/79 (74\%) patients completed the Patient Feedback Form; 51/57 (89\%) patients reported improved communication with health care professionals; and 50/57 (88\%) patients reported improved recollection of symptoms as a result of completing questionnaires.

Conclusion: Based on patient adherence, a low relapse rate, and positive patient attitudes towards completing questionnaires, we concluded that a shared care follow-up, supported by PROs, was a feasible alternative to the standard follow-up for patients with B-cell disease in remission.

Keywords: Hematologic neoplasms, Feasibility study, Supportive care, Patient-reported outcome measures, Nurse-led telephone consultations

\section{Background}

B-cell neoplasms include diseases, such as non-Hodgkin lymphoma, Hodgkin lymphoma, multiple myeloma, and chronic lymphoblastic leukemia (CLL) [1]. These diseases originate in the lymphatic system, and relevant treatments include chemotherapy, with or without immunotherapy, stem cell transplantation, and novel targeted therapies [1-3]. Patients with incurable B-cell neoplasms that do not require immediate, active treatment are sometimes managed with watch and wait (WAW) follow-ups. These patients, and patients in remission after treatment are routinely followed by the attending physician. Clinical guidelines exist for assessing survivors of hematological cancer during follow-up, but the guidelines are inconsistent [1-3]. The follow-up interval and the total post-treatment follow-up time for patients with B-cell neoplasms depend on the specific diagnosis and whether the patient has curable, aggressive lymphoma or chronic, incurable B-cell malignancies, such as indolent lymphoma or CLL. The follow-up strategy can also be influenced by the choice of therapy and the response to treatment; for example, patients at high risk of relapse are closely monitored, due to the potential for suboptimal response to treatment [4]. In Denmark, patients with CLL or indolent lymphoma that are managed with WAW are followed at the outpatient clinic every 4-12 months, and the frequency depends on a number of clinical parameters [5-7]. For example, when patients with diffuse large B-cell lymphoma (DLBCL) respond to a curative intent treatment with complete remission and have a low risk of relapse, they are followed every $3-4$ months in the first year after treatment and every 6 months in the following 2 years; after that, follow-up is terminated. In contrast, patients with a high risk of relapse are typically followed at the outpatient clinic with regular visits for up to 5 years. Similar schedules are applied to patients that receive palliative therapy for incurable B-cell malignancies, but as a rule, follow- ups are lifelong for this group [3]. Post-treatment follow-ups are mainly focused on symptom assessment and physical examinations for signs of recurrent disease $[4,8]$. Patient-reported symptoms are the single most important factors for early detection of recurrent lymphoma, as shown in a previous study, where patientreported symptoms preceded confirmation of lymphoma relapse in $64 \%$ of patients [9]. Follow-up strategies for Bcell neoplasms are based on expert consensus and observational studies, due to the absence of supporting evidence from controlled clinical trials [5-7, 10]. Many patients experience frequent, non-specific symptoms, treatment-related complications, and other healthrelated issues associated with cancer survivorship [1114]. For example, many cancer survivors experience significant fatigue, neuropathy, and anxiety related to a fear of recurrence $[15,16]$; all of these symptoms can have a negative impact on the quality of life [13]. Furthermore, the literature has demonstrated that these patients have reported unmet needs, in particular, emotional and informational needs [17-19]. In recent years, nurse-led interventions have proven successful, in terms of meeting patient needs and addressing psychosocial issues. Additionally, these interventions have demonstrated high patient acceptance and offered advantages, including convenience and individualized care [20-22]. Studies have indicated that PROs can be successfully implemented during the follow-up of patients with cancer; PROs have led to improved patient-provider communication, patient satisfaction, and early relapse detection [23-26]. Moreover, implementing PROs in clinical practice could also support patients in taking an active part in follow-ups and identifying specific health complaints relevant to the individual patient $[27,28]$. Hence, combining nurse-led interventions and collecting PROs on cancer survivorship for patients with hematological cancer might contribute to providing patient-centered care and increase the quality of care. This approach has not 
been sufficiently explored in a hematological setting. Therefore, we investigated the feasibility of a shared care follow-up initiative, with alternating standard physician visits and nurse-led telephone consultations, based on the PROs of patients with B-cell neoplasms.

\section{Methods}

\section{Study design}

This study was designed as a feasibility study. It was conducted from February 2017 to June 2019. Patient recruitment ended in June 2018, and data collection was set to end in December 2018.

\section{Study location}

The study was conducted at the Department of Hematology, Aalborg University Hospital, Denmark. Over the past decade, the number of new patients admitted to this hospital has increased yearly. In 2019, the outpatient clinic served approximately 4000 patients with all varieties of hematological diagnoses, at all stages of the disease trajectory (diagnostics, treatment, and follow-up). Among these patients, approximately 1500 (37.5\%) were diagnosed with B-cell neoplasms.

\section{Study population}

Eligible participants included all patients with B-cell neoplasms that were placed under observation in WAW mode or were previously treated and were currently in post-treatment follow-up. The patients were enrolled by their attending physician at a scheduled in-hospital follow-up visit. The sample size was reached by convenience sampling, and as many eligible patients as possible were included during the recruitment period [29]. All patients provided written signed consent before entering the study.

\section{Study criteria}

Inclusion criteria were: age $\geq 18$ years; a diagnosis of Bcell neoplasm (CLL and lymphomas); disease in remission or stable without treatment for at least 6 months prior to inclusion; sufficient self-care to report new symptoms; and a willingness to return questionnaires on a regular basis. In this context, and based on the WHO's definition of the concept, self-care was defined as the ability of an individual patient to seek hospital care when necessary [30]. Exclusion criteria were: medical conditions, such as severe comorbidities that required close medical attention; conditions that impaired the patient's ability to understand and comprehend the study concept (e.g., dementia); and an inability to complete the questionnaires online.

\section{Follow-up structure}

The nurse-led telephone consultations replaced every other visit with the physician. At the end of every scheduled physician visit, two future consultations were booked, which included one nurse-led telephone consultation and a subsequent in-hospital physician visit. The nurse-led telephone consultations were scheduled ad hoc, and the total number of consultations for each patient was determined by the attending physician, based on the individual follow-up interval and the patient's diagnosis, risk profile, age, and prior treatment. The physician visits were conducted by the three hematologists that participated in the study. The telephone consulting nurse had 15 years of clinical hematology experience.

The patients completed questionnaires at inclusion and prior to every nurse-led consultation. Patients were also asked to complete the questionnaires prior to physician visits, to monitor health-related quality of life (HRQoL) and symptom burden over time; however, physicians were not obliged to review the responses. Patients accessed the questionnaires from an email-alert with a link to an online healthcare platform (Dansk Telemedicin A/S, Denmark). The email-alert was sent 1 week prior to each scheduled nurse-led telephone consultation; when no response was received to the initial email-alert, a reminder was sent after 3 days. The nurse reviewed responses to the individual questions and the overall scores, which were calculated based on questionnaire-specific standard calculations [3133]. Based on the questionnaire responses, the nurse assessed any development or abnormal response and discussed solutions and health-promoting options with the patient during the following telephone conversation. When any health issues were reported that might have been related to the B-cell neoplasm, or when other significant health issues emerged, an in-hospital nurse consultation could be arranged the subsequent day. Alternatively, the patient could be offered a physician consultation at the earliest available time slot. Prior to all types of consultations, routine blood tests were assessed by the physicians.

\section{PRO instruments}

PRO data were collected with three instruments: the European Organization for Research and Treatment of Cancer Quality of Life Questionnaire (EORTC-QLQC30), the Myeloproliferative Neoplasm - Symptom Assessment Form (MPN-SAF), and the Hospital Anxiety and Depression Scale (HADS) [34-36]. EORTC-QLQ-C30 was a 30-item instrument that included an overall Global Health Status domain, five functional domains (physical, emotional, cognitive, social, and role functioning), and nine symptom domains (fatigue, nausea and vomiting, pain, dyspnea, insomnia, appetite loss, constipation, 
diarrhea, and financial difficulties). Each domain was scored from 0 to 100 , and higher scores indicated better HRQoL, better functioning, or a worse symptom burden [37]. MPN-SAF was a 17-item disease-specific symptom questionnaire developed for patients with myeloproliferative diseases [35]. This instrument provided sufficiently generic questions on symptoms relevant to B-cell malignancies; however, no lymphoma-specific questionnaires were available in the local language at the time the study started. Therefore, we added four ad hoc questions to MPN-SAF to ensure that typical B-cell neoplasm symptoms were covered adequately. The ad hoc questions are presented in Table 1. HADS [36] was a 14-item questionnaire designed to assess anxiety and depression symptoms in patients with somatic diseases. HADS included two scales, one for anxiety (HADS-A) and one for depression (HADS-D), to differentiate the two states. Formal licenses for EORTC-QLQ-C30 and HADS were obtained prior to study start [38, 39]. No formal license was required for MPN-SAF, however, written consent for the use of the questionnaire was obtained from the developer [32].

\section{Patient acceptance}

We assessed how well patients accepted the task of completing questionnaires as part of follow-up in a crosssectional survey, conducted between November 2018 and March 2019. Patients were sent an email invitation to participate via the REDCap survey tool [40]. Data were collected with the Patient Feedback Form (PFF), a generic questionnaire that included 13 items for evaluating the applicability and value of PROs in clinical practice. PFF has been translated into Danish and validated by Tolstrup et. al. [41] and written consent to use the questionnaire was obtained from the authors [41]. All participants, including patients that had dropped out of the study for various reasons, were invited to complete the survey. This survey was conducted anonymously to limit a potential response bias and to avoid an overestimation of patient acceptance [42].

Table 1 Ad hoc questions added to MPN-SAF to cover B-cell neoplasm-specific symptoms associated with recurrent disease in a shared care follow-up initiative

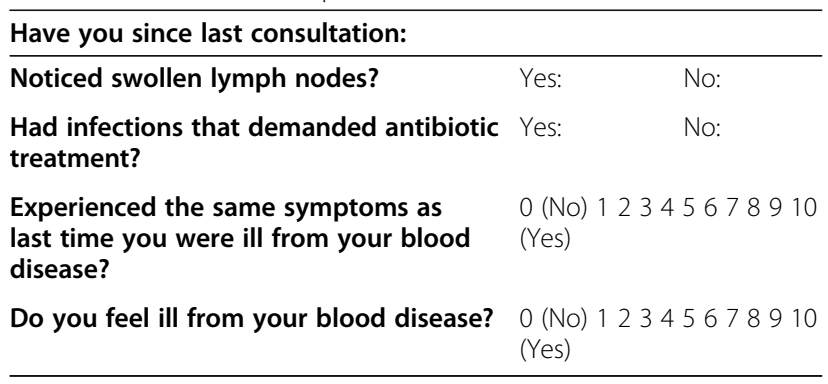

\section{Statistical analyses}

The endpoints were patient inclusion, the questionnaire response rate, the drop-out rate, and patient acceptance of completing questionnaires as a part of the follow-up. We performed descriptive statistics, expressed as the counts (n) and proportions (\%).

\section{Results}

\section{Patient adherence}

Eighty-three patients were invited to participate in the study. The patient inclusion process is illustrated in Fig. 1. Among these, 80 patients agreed to participate; thus, the recruitment rate was $96 \%$ (80/83). Among the 80 included patients (median age 68 years, range $28-82$ ); $42 / 80$ (53\%) were men and 38/80 (48\%) were women. The most frequent B-cell neoplasms were follicular lymphoma (FL; $n=29)$, CLL $(n=17)$, and DLBCL $(n=$ 14). Relevant characteristics of the study population are shown in Table 2. During the study period, 341 questionnaires were distributed. Of these, 335 were completed and returned, which resulted in a response rate of 98\% (335/341).

During follow-up, 5/80 (6\%) patients dropped out of the study due to excessive questions asked $(n=1)$, impaired eyesight, which led to difficulties reading the questionnaires $(n=1)$, and a preference for regular hospital follow-ups $(n=3)$. Another $8 / 80(10 \%)$ patients dropped out of the study due to medical reasons. Of these, 3/80 (4\%) patients experienced a relapse of the Bcell neoplasm. Two relapses (DLBCL) were diagnosed at unscheduled visits requested by the patients, due to the symptoms experienced. The other relapse (MZL) was detected when patient-reported symptoms were reviewed by the study nurse prior to the nurse consultation. Finally, 5/80 (6\%) patients were excluded because closer medical observation was needed due to mental problems $(n=1)$, infections unrelated to B-cell neoplasia activity $(n=2)$, suspicion of relapsed disease raised by an enlarged lymph node, which required regular manual assessments $(n=1)$, and terminal illness, due to another cancer $(n=1)$.

\section{Nurse-led telephone consultations}

During the study period, 129 nurse-led telephone consultations were conducted (median 1 consultations/patient, range $1-4$ ) and the median time spent in a nurse consultation was $12 \mathrm{~min}$ (range 3-67 min). Forty-six patients 46/ 80 (58\%) were followed with one or more nurse-led telephone consultations without further action, and 34/80 (43\%) patients had blood test results or a symptom burden that required discussion with the physician. Five patients $5 / 34$ (15\%) were scheduled for an in-hospital appointment with their attending physician after a discussion between the nurse and the attending physician. Twenty-two 


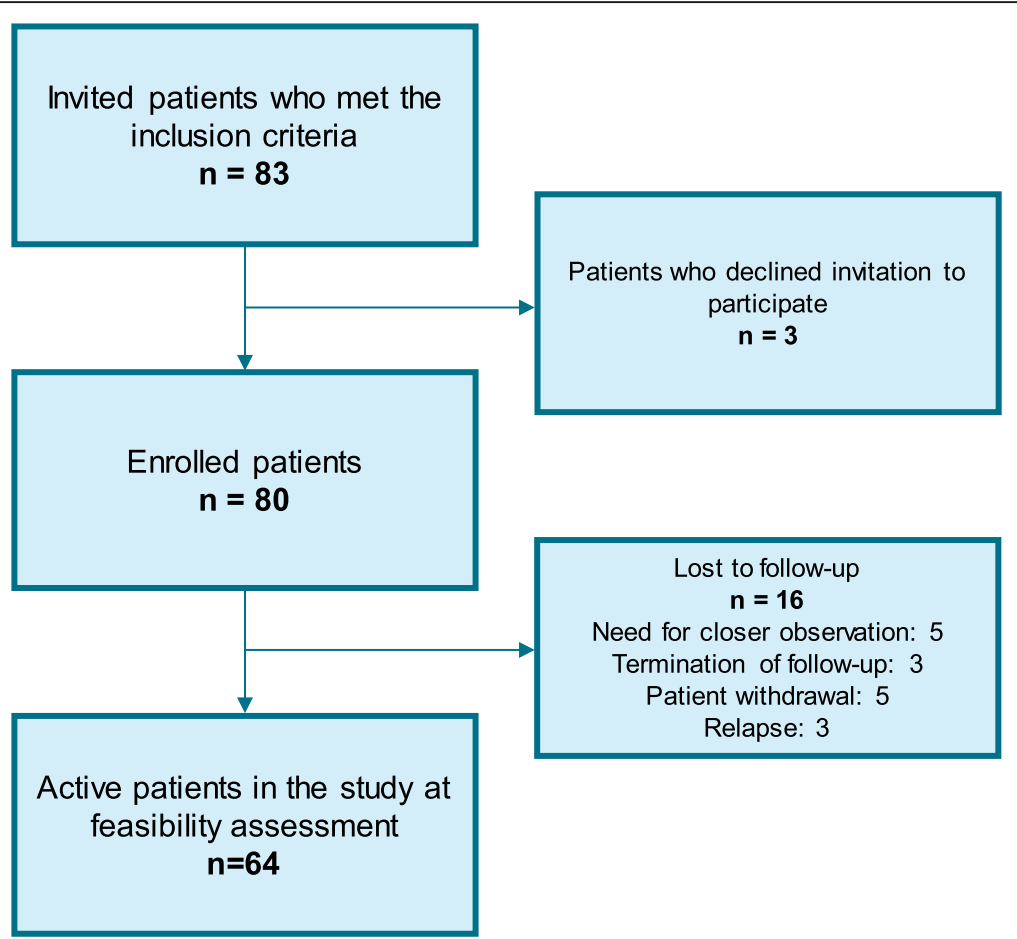

Fig. 1 Flowchart of the patient inclusion process

patients 22/80 (28\%) were advised to seek help from their general practitioner, due to health complaints that were determined to be unrelated to B-cell neoplasia (e.g., dyspnea, urinary issues, musculoskeletal pain). No patients were scheduled for a nurse visit at the outpatient clinic. In total, 124/129 (96\%) nurse-led telephone consultations replaced a visit to the hospital, compared to the standard follow-up procedure.

\section{Patient acceptance}

We conducted a patient acceptance survey to assess attitudes towards completing questionnaires as part of the follow-up. One patient died prior to the survey start, hence $79 / 80$ (99\%) patients were invited to participate. Among these, 58/79 (74\%) patients agreed to participate, including 24/56 (43\%) women and 32/56 (57\%) men (2 patients did not provide gender information). The patient feedback suggested that patients had an overall positive attitude towards completing questionnaires as part of the follow-up. The results from the patient acceptance survey are presented in Table 3.

\section{Discussion}

This study investigated the feasibility of a shared care follow-up initiative, featuring alternating nurse-led telephone consultations, supported by PROs, and regular physician visits, as an alternative to the standard followup for patients treated for B-cell neoplasms. In this study, we found a high recruitment rate of $96 \%(80 / 83)$ and a high questionnaire response rate of 98\% (335/341). Saltbrek et al., tested the feasibility of a nurse-led follow-up among survivors of breast cancer. They reported a recruitment rate of $78 \%$ and a questionnaire response rate of 95.3\% [43]. Furthermore, Beaver et al., tested the feasibility of nurse-led telephone consultations in survivors of prostate cancer. They reported a recruitment rate of $75 \%$ [44]. Hence, our findings were consistent with previous feasibility studies of nurse-led telephone consultations. In fact, our recruitment and questionnaire response rates were higher than those reported in earlier studies. These results suggest that nurseled telephone consultations supported by PROs are feasible among survivors of B-cell cancer. During the study period, five patients withdrew from our study, due to various reasons, which led to a drop-out rate of $6 \%(5 / 80)$. Similarly, Saltbak et al.,and Beaver et a.l, reported dropout rates of 4 and $6.5 \%$, respectively [43, 44], consistent with our findings. These results suggest that survivors of hematological cancer could adhere well to a follow-up model that included nurse-led telephone consultations and PROs. The patients that withdrew from the study varied in age, gender, and diagnosis, which suggested that dropping-out was not driven by specific characteristics. Additionally, only 3/80 (4\%) patients relapsed during the study period, which was a low relapse rate in the selected population. Interestingly, two relapses were discovered by patients. One had clear symptoms that were reported in the questionnaires underscoring the ineffectiveness of 
Table 2 Baseline demographics, treatment, and follow-up characteristics of patients with B-cell neoplasms included in a shared care follow-up initiative

\begin{tabular}{|c|c|}
\hline Characteristic & Total \\
\hline $\mathrm{N}$ & 80 \\
\hline Female & 38 \\
\hline Male & 42 \\
\hline Age, y; median & 68 \\
\hline Age range, y & $28-82$ \\
\hline \multicolumn{2}{|l|}{ Diagnosis } \\
\hline$F L$ & 29 \\
\hline$D L B C L$ & 14 \\
\hline$C L L$ & 17 \\
\hline$M Z L$ & 10 \\
\hline$W M$ & 5 \\
\hline$L P L$ & 3 \\
\hline$M C L$ & 1 \\
\hline$H L$ & 1 \\
\hline Number of visits to a physician, median (range) & $1(0-4)$ \\
\hline Number of nurse consultations, median (range) & $1(0-4)$ \\
\hline Time since diagnosis, y; median (range) & $4.4(1.1-20.2)$ \\
\hline Time since last treatment, $y$; median (range) & $3.4(1.3-16.3)$ \\
\hline \multicolumn{2}{|l|}{ Follow-up interval, months } \\
\hline $2-3$ & 34 \\
\hline $4-5$ & 25 \\
\hline 6 & 21 \\
\hline \multicolumn{2}{|l|}{ Number of treatment lines } \\
\hline 1 & 48 \\
\hline 2 & 4 \\
\hline$>2$ & 4 \\
\hline No previous treatment (watch and wait) & 24 \\
\hline
\end{tabular}

FL Follicular Lymphoma, DLBCL Diffuse Large B-Cell Lymphoma, CLL Chronic Lymphocytic Leukemia, MZL Marginal Zone Lymphoma, WM Waldenstrom Macroglobulinemia, LPL Lymphoblastic Lymphoma, Mantle Cell Lymphoma, HL Hodgkin Lymphoma

routine follow-up in detection of relapse in patients with low risk of relapse. This is consistent with the findings in a recent Danish study showing that patient reported symptoms prereceded relapse detection in the majority of the patients with DLBCL [45]. In total, 10/80 (10\%) patients left the study during the study period due to relapse, a need for closer observation or as a consequence of the patients' choice. Thus, despite targeting patients with high degree of self-care and low risk of relapse, follow-up should be a dynamic process and allow patients to shift between follow-up strategies according to preferences at a given time.
The patients' feedback suggest that most patients found it easier to recall relevant symptoms and found that the conversations with health professionals improved having returned questionnaires. This finding was consistent with those of Greenhalgh et al., who showed that PROs in clinical practice could help support patient-provider communications and patient care. The authors concluded that completing PROs could potentially change the way patients reflected on their health condition [26]. Indeed, we found that, overall, patient acceptance was positive. Although our findings on patient acceptance might not directly reflect the feasibility of the initiative, the patient acceptance did reflect patient perspectives on completing questionnaires as a part of clinical practice.

Our findings on the feasibility of nurse-led telephone consultations were consistent with similar initiatives, which also showed that nurse-led telephone consultations were feasible, efficient, and wellaccepted by patients [20-22, 46]. Most previous studies focused on patients with solid tumors, such as breast, prostate, and/or lung cancer. However, one previous study investigated the feasibility of nurse-led telephone follow-up for patients with indolent and chronic hematological malignancies [47]. Another study tested a model for following-up patients that survived lymphoma [48]. The present study has added evidence to existing studies with our findings that a high recruitment rate and high response rate gave rise to the positive patient adherence in patients that survived hematological cancer. Furthermore, we presented a follow-up model that was based on nurse-led telephone consultations, but with the added requirement that PROs were actively used as a tool for the detection of present health concerns. The systematic use of PROs as preparation for the nurse-led telephone consultations made it possible to provide problem-based consultations and address specific patient concerns at an appropriate time. In addition, the PROs served to prepare the patients for their upcoming consultations, in terms of their awareness of new or persistent symptoms. Consequently, the active, systematic use of PROs prior to any patient contact appeared to be valuable in clinical practice. However, the potential value of the use of PROs should be considered in light of the fact that this joint initiative included both the option to rearrange the follow-up and the addition of PROs; hence, we should not draw conclusions on these components separately. However, the patient feedback suggested that PROs could be valuable, both in clinical practice and in a shared care follow-up initiative, because they enhanced patient reflection on their present symptoms, patientprovider communications, and patient involvement. 
Table 3 Patient Feedback Form results on patient acceptance of completing questionnaires as part of a shared care follow-up initiative for patients treated for B-cell neoplasms

\begin{tabular}{|c|c|c|c|c|c|}
\hline \multirow[t]{2}{*}{ Questions } & \multirow{2}{*}{$\begin{array}{l}\text { Number of } \\
\text { respondents }\end{array}$} & \multicolumn{4}{|c|}{ Responses, N (\%) } \\
\hline & & Too short & $\begin{array}{l}\text { Just } \\
\text { right }\end{array}$ & $\begin{array}{l}\text { Too } \\
\text { long }\end{array}$ & \\
\hline \multirow[t]{2}{*}{ The lengths of the questionnaires were } & 58 & $0(0)$ & $47(81)$ & $11(19)$ & \\
\hline & & $\begin{array}{l}\text { Not often } \\
\text { enough }\end{array}$ & $\begin{array}{l}\text { Just } \\
\text { right }\end{array}$ & $\begin{array}{l}\text { Too } \\
\text { often }\end{array}$ & \\
\hline \multirow[t]{2}{*}{ The number of times I was asked to complete the questionnaires was } & 58 & $0(0)$ & $53(91)$ & $5(9)$ & \\
\hline & & $\begin{array}{l}\text { Strongly } \\
\text { agree }\end{array}$ & Agree & Disagree & $\begin{array}{l}\text { Strongly } \\
\text { Disagree }\end{array}$ \\
\hline It was easy to complete the questionnaires & 58 & $15(26)$ & $36(62)$ & $7(12)$ & $0(0)$ \\
\hline It made sense to complete the questionnaires & 58 & $16(28)$ & $36(62)$ & $5(9)$ & $1(2)$ \\
\hline It was easy to understand the questions & 58 & $18(31)$ & $36(62)$ & $4(7)$ & $0(0)$ \\
\hline $\begin{array}{l}\text { Completing the questionnaires made it easier for me to remember my } \\
\text { symptoms and side effects, when I spoke with the healthcare professionals }\end{array}$ & 57 & $15(26)$ & $35(61)$ & $7(12)$ & $0(0)$ \\
\hline $\begin{array}{l}\text { Completing the questionnaires improved the conversation with the health care } \\
\text { professionals }\end{array}$ & 57 & $14(25)$ & $37(65)$ & $6(11)$ & $0(0)$ \\
\hline $\begin{array}{l}\text { The health care professionals used the information from the questionnaires in } \\
\text { connection with my treatment }\end{array}$ & 54 & $15(28)$ & $30(56)$ & $9(17)$ & $0(0)$ \\
\hline $\begin{array}{l}\text { It is my experience that the quality of my treatment was improved due to the } \\
\text { fact that I had completed the questionnaires }\end{array}$ & 54 & $9(17)$ & $35(65)$ & $10(19)$ & $0(0)$ \\
\hline $\begin{array}{l}\text { It is my experience that the communication with the health care professionals } \\
\text { was improved due to the fact that I had completed the questionnaires }\end{array}$ & 55 & $9(16)$ & $35(64)$ & $11(20)$ & $0(0)$ \\
\hline Completing the questionnaires made me feel involved in my treatment & 56 & $18(32)$ & $30(54)$ & $8(14)$ & $0(0)$ \\
\hline I would recommend that other patients should complete the questionnaires & 56 & $23(41)$ & $32(57)$ & $1(2)$ & $0(0)$ \\
\hline I would like to continue completing questionnaires in the future & 54 & $24(44)$ & $24(44)$ & $4(7)$ & $2(4)$ \\
\hline
\end{tabular}

Although we found that this follow-up model was feasible, and we observed positive patient adherence, the study was conducted without a control group. Therefore, we could not conclude whether this initiative improved the quality of care or patient satisfaction over the standard follow-up.

It has been demonstrated that some patients declined participation in telehealth interventions, because they felt unsure about using technology or they had concerns about privacy [49, 50]. This suggested that a large number of declined invitations to participate could contribute to an overestimation of the feasibility of the intervention. In the present study, we did not determine the reasons for declining participation. Although this is important knowledge, only three patients declined participation after receiving detailed information about the study by the study nurse. This low decline rate suggested that the concerns of those patients did not significantly influence our estimation of study feasibility.

In this study, the patients were selected by their attending physicians, which might have contributed to that the patients' refrained from declining participation.
However, in order to limit potential influence from the physician - patient relationship, strong emphasis was placed on the fact that participation was voluntary and that the patients could return to in-hospital follow-up without any consequences for future treatment and care.

The sample size was achieved by convenience sampling [29, 51]; we included as many patients possible during the study period. The shared care follow-up initiative was offered as an optional service for interested patients, and it did not plan to include patients that felt more secure with in-hospital visits. However, convenience sampling poses the risk of a selection bias. The main assumption of this sampling method is that the target population is homogeneous, compared to random sampling methods [29, 51]. Consequently, our sample might have been too homogeneous to generalize results to other patient populations. However, by including 80 patients, we attempted to increase the likelihood of including a heterogeneous study population [52]. Indeed, some heterogeneity was achieved, based on the age range of the included patients and the range of disease types. However, the size of the study population was insufficient to provide powered, meaningful subgroup 
analyses of individual diagnostic categories or age groups. Furthermore, the limited drop-out rate did not allow an exploration of the features associated with the likelihood of completing the study.

\section{Conclusion}

To provide evidence for revising the standard follow-up procedure, we tested the feasibility of a shared care follow-up initiative, supported by PROs, for patients with B-cell neoplasms. We found good patient adherence, in terms of a high recruitment rate, a high response rate, and a low drop-out rate. Furthermore, relapse detection did not seem to be compromised. Patient feedback suggested that patients had an overall positive attitude towards completing questionnaires as part of the follow-up. In conclusion, a shared care follow-up initiative supported by PROs for patients with B-cell neoplasms in remission appeared to be feasible and acceptable as an alternative to standard practice for a patient population with a perceived high level of selfcare and low risk of relapse. The inclusion of PROs in the post-treatment follow-up was a valuable addition, in terms of increasing reflection on the patient's own health, enhancing patient-provider communications, and encouraging patient involvement. Although further research is warranted, including an exploration of patient experiences, based on our results, the systematic use of PROs could potentially offer a more individualized, problem-based approach to nurse-led consultations and provide support for more meaningful, relevant physician consultations. Future studies should explore the cost effectiveness of this proposed model of shared care followup. In addition, other aspects of PRO use should be evaluated in the follow-up of patients with B-cell neoplasms, such as the potential for promoting early detection of relapse or progressive disease in a more high-risk population.

\footnotetext{
Abbreviations

PRO: Patient-reported outcome; EORTC-QLQ-C30: The European Organization for Research and Treatment of Cancer - Quality of Life Questionnaire - 30 questions; MPN-SAF: Myeloproliferative Neoplasm - Symptom Assessment Form; HADS: Hospital Anxiety and Depression Scale; PFF: Patient Feedback Form; CLL: Chronic Lymphocytic Leukemia; WAW: Watch and wait; HRQOL: Health-related quality of life; FL: Follicular Lymphoma; DLBCL: Diffuse Large B-Cell Lymphoma
}

\section{Acknowledgements}

We acknowledge the participating patients and clinicians at the Department of Hematology, Aalborg University Hospital, Denmark. We also thank June Chalotte Korup and Majbritt Bøgh Riis, who supported the study throughout the study period. Furthermore, we would like to thank Hasselbalch \& Lykkegaard Andersen's Research Fundation, for granting access to the digital platform, and the Department of Hematology, Roskilde Hospital, Denmark, for advice during the project set-up phase. Finally, we would like to acknowledge our late Professor, Hans Erik Johnsen for scientific support and advice.

\section{Authors' contributions}

$M S, L F, P W, S N$, and TE contributed to the design of the study. $L N, R B, M B$, and MS performed the statistical analyses, which were interpreted by MS, LN, $R B, M B, J M, M T S, E E S, M G$ and TE. All authors contributed to writing the manuscript, and all authors read and approved the final manuscript.

\section{Funding}

This study was partly funded by Region Nordjylland, Denmark.

\section{Availability of data and materials}

The datasets used and/or analyzed during the current study are available from the corresponding author on reasonable request.

\section{Ethics approval and consent to participate}

This study was approved by the National Data Protection Agency (jour. no. 2008-58-0028). An assessment by the Health Ethics Committee of the North Denmark Region deemed the study to be focused on quality improvement; therefore, it was exempted from formal ethical approval, according to Danish legislation. All patients provided written signed consent before entering the study.

\section{Consent for publication}

Not applicable to this study.

\section{Competing interests}

All authors report no competing interests related to the research presented in this manuscript.

\section{Author details}

'Department of Hematology, Aalborg University Hospital, Sdr. Skovvej 15, DK-9000 Aalborg, Denmark. ${ }^{2}$ Department of Clinical Medicine, Aalborg University, Aalborg, Denmark. ${ }^{3}$ Clinical Nursing Research Unit, Aalborg University Hospital, Aalborg, Denmark. ${ }^{4}$ Clinical Cancer Research Center, Aalborg University Hospital, Aalborg, Denmark.

Received: 25 May 2020 Accepted: 3 November 2020

Published online: 17 November 2020

\section{References}

1. Eichhorst B, Robak T, Montserrat E, Ghia P, Hillmen P, Hallek M, et al. Chronic lymphocytic leukaemia: ESMO clinical practice guidelines for diagnosis, treatment and follow-up t. ESMO Updat Clin Pract Guidel. 2015; 26:v78-84.

2. Zucca E, Arcaini L, Buske C, Johnson PW, Ponzoni M, Raderer M, et al. Marginal zone lymphomas: ESMO clinical practice guidelines for diagnosis, treatment and follow-up. Ann Oncol. 2020;31(1):17-29.

3. Tilly H. Gomes Da Silva M, Vitolo U, Jack a, Meignan M, Lopez-Guillermo a, et al. diffuse large B-cell lymphoma (DLBCL): ESMO clinical practice guidelines for diagnosis, treatment and follow-up t. ESMO Updat Clin Pract Guidel. 2015;26:v116-25.

4. Sundhedsstyrelsen. Opfølgningsprogram for lymfeknudekræft og kronisk lymfatisk leukæmi (Follow-up of lymphoma and chronic lymphatic leukemia). 2015. Available from: https://www.sst.dk/-/media/Udgivelser/ 2019/Pakkeforloeb-kraeft-2015-2019/Opfølgningsprogrammer-for-kræft2015/Opfølgningsprogram-for-lymfeknudekræft-og-kronisk-lymfatiskleukæmi---FINAL.ashx?la=da\&hash= A502C520C59B1D807BB6E2508C341C0B4F6E69D1.

5. Jørgensen, J, Madsen, J, Hansen P et al. Danish lymphoma group: National Guidelines for treatment of diffuse large B-cell lymphoma. 2015. Available from: http://www.lymphoma.dk/wp-content/uploads/2016/11/ DLBCLRekommandationer2015ver2_1.pdf.

6. Bentzen $H$, Vissing $K$, Munksgaard $L$, Do $T$, Jensen $P$, Pedersen $M$, et al. Danish lymphoma group: guidelines for diagnosing, treatment and followup of follicular lymphoma. 2015. Available from: http:/www.lymphoma.dk/ wp-content/uploads/2016/11/Follikulä,rt_lymfom_guidelines_2015.pdf.

7. Christiansen, I; Pulczynski, El;Gillström D et al. Danish Lymphoma Group: National guidelines for treatment of chronic lymphatic leukemia. 2016. Available from: http://www.lymphoma.dk/retningslinjer/.

8. Høeg BL, Bidstrup PE, Allerslev Horsboel T, Dalton SO, Saltbaek L, Karlsen RV, et al. Follow-up strategies following completion of primary cancer treatment in adult cancer survivors. Cochrane Database Syst Rev. 2019;11. 
9. El-Galaly T, Mylam KJ, Bøgsted M, Brown P, Rossing M, Gang AO, et al. Role of routine imaging in detecting recurrent lymphoma: a review of 258 patients with relapsed aggressive non-Hodgkin and Hodgkin lymphoma. Am J Hematol. 2014;89(6):575-80.

10. Schöllkopf, C, Weber, D, Sengeløv H et al. Acute leukemia group Denmark: National Guidelines for treatment of acute myeloid leukemia. 2015. Available from: https://hematology.dk/index.php/vejledninger/kliniske/2 012-11-06-06-19-25/43-aml/file.

11. Allart-Vorelli P, Porro B, Baguet F, Michel A, Cousson-Gélie F. Haematological cancer and quality of life: a systematic literature review. Blood Cancer J. 2015;5(4):e305.

12. Firkins J, Hansen L, Driessnack M, Dieckmann N. Quality of life in "chronic" cancer survivors: a meta-analysis. J Cancer Surviv. 2020;14:504-17.

13. Götze H, Taubenheim S, Dietz A, Lordick F, Mehnert A. Comorbid conditions and health-related quality of life in long-term cancer survivors-associations with demographic and medical characteristics. J Cancer Surviv. 2018;12(5): 712-20.

14. Korszun A, Sarker SJ, Chowdhury K, Clark C, Greaves P, Johnson R, et al. Psychosocial factors associated with impact of cancer in longterm haematological cancer survivors. Br J Haematol. 2014;164(6):790-803.

15. Hall A, Campbell HS, Sanson-Fisher R, Lynagh M, D'Este C, Burkhalter R, et al. Unmet needs of Australian and Canadian haematological cancer survivors: a cross-sectional international comparative study. Psychooncology. 2013;22(9): 2032-8.

16. Götze H, Köhler N, Taubenheim S, Lordick F, Mehnert A. Polypharmacy, limited activity, fatigue and insomnia are the most frequent symptoms and impairments in older hematological cancer survivors (70+): findings from a register-based study on physical and mental health. J Geriatr Oncol. 2019; 10(1):55-9.

17. Swash B, Hulbert-Williams N, Bramwell R. Unmet psychosocial needs in haematological cancer: a systematic review. Vol. 22. Support Care Cancer. 2014;22(4):1131-41.

18. Lobb EA, Joske D, Butow P, Kristjanson LJ, Cannell P, Cull G, et al. When the safety net of treatment has been removed: patients' unmet needs at the completion of treatment for haematological malignancies. Patient Educ Couns. 2009:77(1):103-8

19. Oberoi D, White $V$, Seymour J, Miles Prince $H$, Harrison S, Jefford M, et al. The course of anxiety, depression and unmet needs in survivors of diffuse large B cell lymphoma and multiple myeloma in the early survivorship period. J Cancer Surviv. 2017;11(3):329-38.

20. Lewis R, Neal RD, Williams NH, France B, Wilkinson C, Hendry M, et al. Nurse-led vs. conventional physician-led follow-up for patients with cancer: systematic review. J Adv Nurs. 2009;65(4):706-23.

21. Cox K, Wilson E. Follow-up for people with cancer: nurse-led services and telephone interventions. J Adv Nurs. 2003;43(1):51-61.

22. Suh S-R, Lee MK. Effects of nurse-led telephone-based supportive interventions for patients with Cancer: a meta-analysis. Oncol Nurs Forum. 2017;44(4):E168-84.

23. Chen J, Ou L, Hollis SJ. A systematic review of the impact of routine collection of patient reported outcome measures on patients, providers and health organisations in an oncologic setting. BMC Health Serv Res. 2013; 13(1):211.

24. Gotay CC, Kawamoto CT, Bottomley A, Efficace F. The prognostic significance of patient-reported outcomes in Cancer clinical trials. J Clin Oncol. 2008:26(8):1355-63.

25. Basch E, Deal AM, Kris MG, Scher HI, Hudis CA, Sabbatini P, et al. Symptom monitoring with patient-reported outcomes during routine Cancer treatment: a randomized controlled trial. J Clin Oncol. 2016; 34(6):557-65.

26. Greenhalgh J, Gooding K, Gibbons E, Dalkin S, Wright J, Valderas J, et al. How do patient reported outcome measures (PROMs) support clinicianpatient communication and patient care? A realist synthesis. J Patient Rep Outcomes. 2018;2(42):26.

27. Claire Snyder BF, Herman JM, White SM, Luber BS, Blackford AL, Carducci MA, et al. When using patient-reported outcomes in clinical practice, the measure matters: a randomized controlled trial. J Oncol Pract. 2014;10(5): e299-306.

28. Snyder CF, Aaronson NK, Choucair AK, Elliott TE, Greenhalgh J, Halyard MY et al. Implementing patient-reported outcomes assessment in clinical practice: a review of the options and considerations. Qual Life Res. 2012; 21(8):1305-14
29. Etikan I. Comparison of convenience sampling and purposive sampling. Am J Theor Appl Stat. 2016;5(1):1.

30. World Health Organization $(\mathrm{WHO})$. Self-care interventions for health. Available from: https://www.who.int/health-topics/self-care\#tab=tab_1. Accessed 26 July 2020

31. Fayers PM, Aaronson NK, Bjordal K, Groenvold M, Curran DBA. EORTC QLQC30 scoring manual (3rd edition). Brussels: European Organisation for Research and Treatment of Cancer; 2001.

32. Emanuel RM, Dueck AC, Geyer HL, Kiladjian J-J, Slot S, Zweegman S, et al. Myeloproliferative neoplasm (MPN) symptom assessment form total symptom score: prospective international assessment of an abbreviated symptom burden scoring system among patients with MPNs. J Clin Oncol. 2012;30(33):4098-103.

33. Snaith RP, Zigmond AS. The hospital anxiety and depression manual. London: GL Assessment; 1994.

34. Aaronson NK, Ahmedzai S, Bergman B, Bullinger M, Cull A, Duez NJ, et al. The European Organization for Research and Treatment of Cancer QLQ-C30: a quality-of-life instrument for use in international clinical trials in oncology. J Natl Cancer Inst. 1993;85(5):365-76.

35. Scherber R, Dueck AC, Johansson P, Barbui T, Barosi G, Vannucchi AM, et al. The Myeloproliferative neoplasm symptom Assessment form (MPN-SAF): international prospective validation and reliability trial in 402 patients. Blood. 2011;118(2):401-8.

36. Zigmond AS, Snaith RP. The hospital anxiety and depression scale. Acta Psychiatr Scand. 1983;67(6):361-70.

37. Sprangers MA, Cull A, Bjordal K, Groenvold M, Aaronson NK. The European Organization for Research and Treatment of Cancer. Approach to quality of life assessment: guidelines for developing questionnaire modules. EORTC study group on quality of life. Qual Life Res. 1993;2(4): 287-95.

38. The European Organisation for Research and Treatment of Cancer. EORTC Study Tools. Available from: https://www.eortc.org/tools/. Accessed 30 Oct 2020

39. GL Assessment. Hospital Anxiety and Depression Scale (HADS) A reliable self-rating scale that measures anxiety and depression. Available from: https://www.gl-assessment.co.uk/products/hospital-anxiety-and-depressionscale-hads/. Accessed 30 Oct 2020

40. Vanderbilt. Software - REDCap. Available from: https://projectredcap.org/ software/. Accessed 10 Feb 2020

41. Tolstrup LK, Pappot H, Zangger G, Bastholt L, Zwisler A-D, Dieperink KB. Danish translation, cultural adaption and initial psychometric evaluation of the patient feedback form. Health Qual Life Outcomes. 2018;16(1):77.

42. Mazor KM, Clauser BE, Field T, Yood RA, Gurwitz JH. A demonstration of the impact of response bias on the results of patient satisfaction surveys. Health Serv Res. 2002;37(5):1403-17.

43. Saltbæk L, Karlsen RV, Bidstrup PE, Høeg BL, Zoffmann V, Horsbøl TA, et al. MyHealth: specialist nurse-led follow-up in breast cancer. A randomized controlled trial - development and feasibility. Acta Oncol (Madr). 2019;58(5):619-26.

44. Beaver K, Campbell M, Williamson S, Procter D, Sheridan J, Heath J, et al. An exploratory randomized controlled trial comparing telephone and hospital follow-up after treatment for colorectal cancer. Color Dis. 2012;14(10):1201-9

45. El-Galaly TC, Jakobsen LH, Hutchings M, de Nully BP, Nilsson-Ehle H, Székely $\mathrm{E}$, et al. Routine imaging for diffuse large B-cell lymphoma in first complete remission does not improve post-treatment survival: a Danish-Swedish population-based study. J Clin Oncol. 2015;33(34):3993-8.

46. Casey R, Powell L, Braithwaite M, Booth C, Sizer B, Corr J. Nurse-led phone call follow-up clinics are effective for patients with prostate Cancer. J Patient Exp. 2017:4(3):114-20

47. Overend A, Khoo K, Delorme M, Krause V, Avanessian A, Saltman D. Evaluation of a nurse-led telephone follow-up clinic for patients with indolent and chronic hematological malignancies: a pilot study. Can Oncol Nurs J. 2008;18(2):64-73.

48. Compaci G, Rueter M, Lamy S, Oberic L, Recher C, Lapeyre-Mestre M, et al. Ambulatory medical assistance - after Cancer (AMA-AC): a model for an early trajectory survivorship survey of lymphoma patients treated with anthracycline-based chemotherapy. BMC Cancer. 2015;15(1):781.

49. Sanders C, Rogers A, Bowen R, Bower P, Hirani S, Cartwright M, et al. Exploring barriers to participation and adoption of telehealth and telecare within the whole system demonstrator trial: a qualitative study. BMC Health Serv Res. 2012;12(1):220. 
50. Foster A, Horspool KA, Edwards L, Thomas CL, Salisbury C, Montgomery AA, et al. Who does not participate in telehealth trials and why? A crosssectional survey. Trials. 2015;16(1):50.

51. Elfil M, Negida A. Sampling methods in clinical research; an educational review. Emergency. 2017;5(1):52.

52. Billingham SA, Whitehead AL, Julious SA. An audit of sample sizes for pilot and feasibility trials being undertaken in the United Kingdom registered in the United Kingdom clinical research network database. BMC Med Res Methodol. 2013;13(1):104.

\section{Publisher's Note}

Springer Nature remains neutral with regard to jurisdictional claims in published maps and institutional affiliations.

Ready to submit your research? Choose BMC and benefit from:

- fast, convenient online submission

- thorough peer review by experienced researchers in your field

- rapid publication on acceptance

- support for research data, including large and complex data types

- gold Open Access which fosters wider collaboration and increased citations

- maximum visibility for your research: over $100 \mathrm{M}$ website views per year

At $\mathrm{BMC}$, research is always in progress.

Learn more biomedcentral.com/submissions 